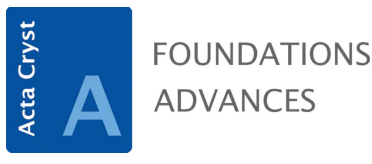

ISSN 2053-2733
Received 20 February 2020

Accepted 9 June 2020

Edited by D. A. Keen, STFC Rutherford Appleton Laboratory, United Kingdom

Keywords: confined water; bioactive glasses; structural analysis; pair distribution function.

Supporting information: this article has supporting information at journals.iucr.org/a

\section{X-ray scattering study of water confined in bioactive glasses: experimental and simulated pair distribution function}

\author{
Hassan Khoder, Dominik Schaniel, Sébastien Pillet and El-Eulmi Bendeif*
}

Université de Lorraine, CNRS, CRM2, Nancy, France. *Correspondence e-mail: el-eulmi.bendeif@univ-lorraine.fr

Temperature-dependent total X-ray scattering measurements for water confined in bioactive glass samples with $5.9 \mathrm{~nm}$ pore diameter have been performed. Based on these experimental data, simulations were carried out using the Empirical Potential Structure Refinement (EPSR) code, in order to study the structural organization of the confined water in detail. The results indicate a non-homogeneous structure for water inside the pore, with three different structural organizations of water, depending on the distance from the pore surface: (i) a first layer ( $4 \AA$ ) of interfacial pore water that forms a strong chemical bond with the substrate, (ii) intermediate pore water forming a second layer (4-11 $\AA$ ) on top of the interfacial pore water, (iii) bulk-like pore water in the centre of the pores. Analysis of the simulated site-site partial pair distribution function shows that the water-silica $\left(\mathrm{O}_{\mathrm{w}}-\mathrm{Si}\right)$ pair correlations occur at $\sim 3.75 \AA$. The tetrahedral network of bulk water with oxygen-oxygen $\left(\mathrm{O}_{\mathrm{w}}-\right.$ $\mathrm{O}_{\mathrm{w}}$ ) hydrogen-bonded pair correlations at $\sim 2.8, \sim 4.1$ and $\sim 4.5 \AA$ is strongly distorted for the interfacial pore water while the second neighbour pair correlations are observed at $\sim 4.0$ and $\sim 4.9 \AA$. For the interfacial pore water, an additional $\mathrm{O}_{\mathrm{w}}-\mathrm{O}_{\mathrm{w}}$ pair correlation appears at $\sim 3.3 \AA$, which is likely caused by distortions due to the interactions of the water molecules with the silica at the pore surface.

\section{Introduction}

A new stage in the development of materials having biomedical applications began in 1969, when Professor Larry Hench discovered the bioactive glasses (Hench et al., 1971). Using these materials, significant therapeutical progress has been achieved for bone repair and replacement (Hench \& Wilson, 1984; Hench \& Polak, 2002; Izquierdo-Barba et al., 2008).

The biomedical applications of these bioactive glasses are mainly due to their high biocompatibility and high reactivity with the human physiological environment, since the reaction products obtained from these bioactive glasses and the physiological fluids lead to the deposition of a layer of crystalline bone-like carbonate calcium phosphate (hydroxycarbonate apatite, HCA) on their surface shortly after interaction (Turdean-Ionescu et al., 2016). Therefore, the glass bioactivity is usually evaluated by measuring the rate of HCA formation at the bioactive glass surface on its exposure either to body fluids in vivo or to a simulated body fluid (SBF) in vitro.

The glass composition of the first melt-derived bioactive glass discovered by Hench was 45S5: 46.1\% $\mathrm{SiO}_{2}, 24.4 \% \mathrm{NaO}$, $26.9 \% \mathrm{CaO}$ and $2.6 \% \mathrm{P}_{2} \mathrm{O}_{5}$, in mol. \% . This discovery launched extensive research in the field of bioactive glasses, producing various compositions and types that are bioactive (Jones et al., 
2006). It has been reported that the sol-gel-derived glasses within the system $\mathrm{Na}_{2} \mathrm{O}-\mathrm{CaO}-\mathrm{SiO}_{2}$ show bioactivity within a much larger composition range than melt-derived glasses $(\mathrm{Li}$ et al., 1991). For a melt-derived glass, the silica content has to be less than $60 \mathrm{~mol}$ \% for it to have a bioactive property, while for a sol-gel-derived glass the silica content can be up to 90 mol.\% (Li et al., 1991). Since then, sol-gel bioactive glasses have been studied intensively (Jones, 2013; Salinas \& ValletRegí, 2013; Kaur et al., 2016).

Because these materials are intended to interact with body fluids, the understanding of the impact of confinement on the organization and diffusion of physiological fluids encapsulated in these nanomaterials is crucial for improving their properties. Given that the physiological fluids are composed mostly of water, it is of interest to study the structure and properties of water confined in bioactive glasses as model systems.

The structural and dynamic properties of water confined in a limited volume can be different from those of the bulk due to the water-substrate interactions and the geometrical confinement. Therefore, many studies have been devoted to understanding the confinement effect of water on its thermodynamic, dynamic and structural properties, using different techniques, such as differential scanning calorimetry (DSC) (Schreiber et al., 2001; Kittaka et al., 2006, 2009), X-ray diffraction (XRD) (Morishige \& Kawano, 1999; Morishige \& Iwasaki, 2003; Morishige et al., 2007), nuclear magnetic resonance (NMR) (Webber et al., 2007; Akporiaye et al., 1994; Hansen et al., 1995) as well as neutron scattering (Yoshida $e t$ al., 2008; Takahara et al., 1999; Faraone et al., 2004). In particular, many studies have been focused on the behaviour of water confined in porous silica (Takamuku et al., 1997; Steytler et al., 1983; Bellissent-Funel et al., 1993; Bogdan et al., 1998; Tombari et al., 2005).

Over the past three decades, a wide range of porous materials with different characteristics with respect to pore sizes, pore volume and specific surface area has become available. For example, porous silica with different sizes and uniform pore shapes such as MCM-41 (Kresge et al., 1992) and SBA-15 (Zhao et al., 1998) have been developed using various forms of surfactant micelles, which has led to remarkable progress in the experimental and theoretical studies of porous systems (Morishige \& Uematsu, 2005; Alba-Simionesco et al., 2006; Ravikovitch et al., 1995; Ravikovitch \& Neimark, 2001).

Among the most salient features found for water confined in porous silica is the existence of two types of confined water: freezable and non-freezable pore water (Schreiber et al., 2001; Rennie \& Clifford, 1977; Ishikiriyama \& Todoki, 1995; Schmidt et al., 1995; Hansen et al., 1997). The freezable pore water has phase transitions (freezing and melting) that occur at temperatures much lower than for bulk water. It has been observed that the phase transition temperatures are strongly related to the pore size, i.e. the smaller the pores, the lower the temperatures. Furthermore, other studies have demonstrated that the freezing of the pore water leads to the formation of cubic ice $\mathrm{I}_{\mathrm{c}}$, instead of hexagonal $\mathrm{I}_{\mathrm{h}}$ (Takamuku et al., 1997; Bellissent-Funel et al., 1993).
Surprisingly, several exothermic peaks have been observed by DSC measurements and attributed to a non-homogeneous freezing process for confined water due to the coexistence of different species of confined water in the narrow pores, which have different structural organizations depending on water loading and pore size distribution (Schreiber et al., 2001; Findenegg et al., 2008). To understand the properties of these species, one needs an appropriate approach that allows the structural analysis of the confined water.

Here, we present the detailed structural analysis of confined water inside a mesoporous bioactive glass. This study is based on total X-ray scattering data coupled with pair distribution function (PDF) analysis and on modelling the structure using the refinement of an empirical potential. Through the study of the site-site partial pair distribution functions, the pair correlations along with the structure of the confined water can be described accurately. These results will be further compared with the bulk water structure.

\section{Materials and methods}

\subsection{Sample characterization}

The microfluidic bioactive glass (hereafter called 92S6) with $5.9 \mathrm{~nm}$ pore diameter was prepared according to the procedure previously reported (Bchellaoui et al., 2017). The synthesis is based on a new microfluidic-assisted sol-gel method for the fabrication of mesoporous silica microcapsules with a highly controlled particle size in the micrometre range. The $92 \mathrm{~S} 6$ sample has a molar composition of $92 \% \mathrm{SiO}_{2}, 2 \%$ $\mathrm{CaO}$ and $6 \% \mathrm{P}_{2} \mathrm{O}_{5}$ mol.\%. The mesoporous organization has been characterized using the small-angle X-ray scattering (SAXS) technique and showed a well ordered hexagonal distribution of cylindrical nanopores in the 92S6 sample (see Fig. S1 in the supporting information). Bchellaoui and coworkers (Bchellaoui et al., 2017) have reported the textural parameters of the sample: pore diameter of $5.9 \mathrm{~nm}$, specific surface area of $514 \mathrm{~m}^{2} \mathrm{~g}^{-1}$ and specific pore volume of $0.76 \mathrm{~cm}^{3} \mathrm{~g}^{-1}$.

\subsection{Water loading process}

First, samples were oven-dried at $473 \mathrm{~K}$ for $72 \mathrm{~h}$ to remove all residual water. Second, monitored controlled wetting of the sample was realized by adding a precisely weighed amount of water to a known amount of dry sample. The water loading is defined as the ratio between the added water volume and the pore volume, $\%=V_{\text {water }} / V_{\text {pores }}$ (hereafter, wetted samples are called $x \% 92 \mathrm{~S} 6$, with $x$ the water loading volume ratio). Finally, wetted samples were stored at room temperature for $72 \mathrm{~h}$ before the measurements were performed in order to ensure a homogeneous distribution of water inside the pores. Each sample was sealed in a Kapton capillary with $1 \mathrm{~mm}$ diameter.

\subsection{Water loading ratios}

In order to follow the structural changes induced by the amount of confined water, samples were prepared with three different water loadings (30, 60 and 100 vol.\%). These ratios 
were chosen based on additional DSC measurements that have been performed for another research purpose currently in publication. The results showed that two or more exothermic peaks appear on the cooling curves depending on the water loading, while a single large endothermic peak appears on the heating curves. This indicates the coexistence of different phases and structural organization of confined water. For low water content ( 30 vol. \%), the interfacial pore layer is filled first. On increasing the amount of water (60 vol.\%), additional layers cover the interfacial adsorbed water. These new layers form the 'intermediate' pore water and exhibit different thermodynamic properties. On overloading with high water content (100 vol.\%), bulk-like water thermodynamic properties are observed. Therefore, based on these results, the same loading ratios were chosen for further structural investigation.

\subsection{Total X-ray scattering}

Total X-ray scattering measurements were performed on the CRISTAL beamline at the SOLEIL synchrotron facility and on the ID31 beamline at the ESRF, using monochromatic radiation with energies $E=28.3988 \mathrm{keV}(\lambda=0.43696 \AA)$ and $E=68.5 \mathrm{keV}(\lambda=0.18099 \AA)$, respectively. These data were collected at different temperatures ranging from 293 to $200 \mathrm{~K}$. Fig. 1 shows the raw scattering data for water confined in $92 \mathrm{~S} 6$ with three different water loadings at different temperatures. The obtained results are in agreement with other studies reported in the literature for supercooled confined water (Soper, 2008, 2012, 2013).

Stefanutti et al. (2019) studied the state of supercooled water confined in MCM-41 using neutron scattering. They

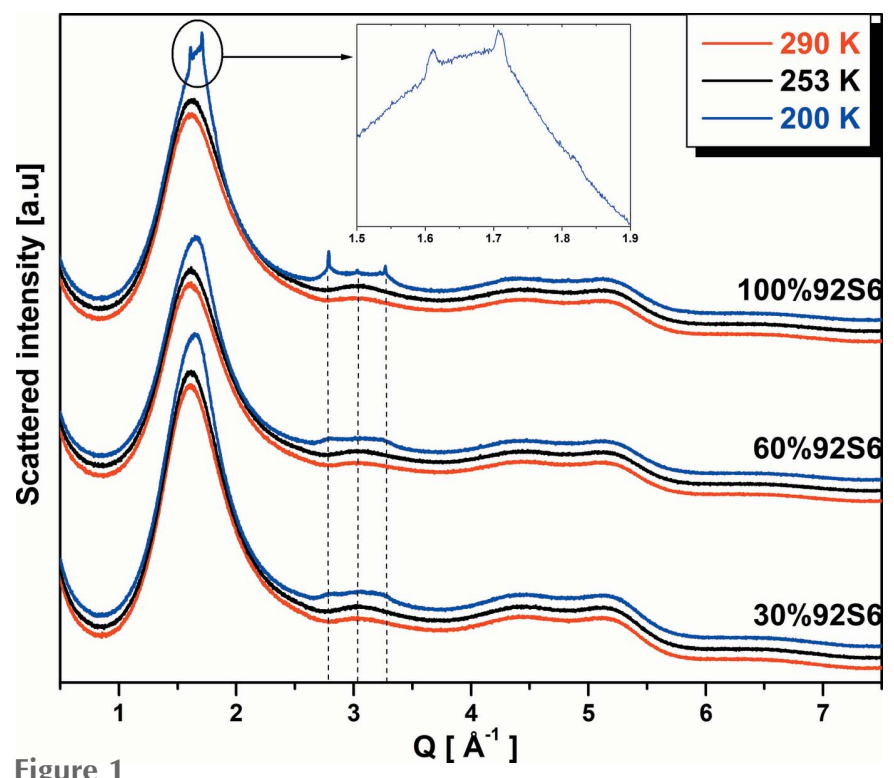

Figure 1

Raw scattering intensity $I(Q)$ for confined water with: $30 \% 92 \mathrm{~S} 6$ (bottom), 60\%92S6 (middle), 100\%92S6 (top). For each sample, three temperatures are presented: $290,253,200 \mathrm{~K}$. The inset shows positions of the main peaks around $Q=1.7 \AA^{-1}$. The scattering curves for 253 and $200 \mathrm{~K}$ are shifted vertically with respect to the scattering curve at ambient temperature for clarity. have shown the coexistence of freezable pore water with a layer of non-freezable pore water by analysing the change in the Bragg peak intensities. As shown in Fig. 1, for the three water loadings, when decreasing the temperature to $253 \mathrm{~K}$, no significant change appears in the scattering intensity, showing that the added amount of water is totally confined. On the other hand, after cooling the samples to $200 \mathrm{~K}$, the intensity of the main peak at $1.6 \AA^{-1}$ increases in both $30 \%$ and $60 \% 92 \mathrm{~S} 6$ samples, accompanied by the appearance of two peaks with low intensity at 2.8 and $3.28 \AA^{-1}$, suggesting the crystallization or the solidification of some of the confined water. The $100 \% 92$ S6 sample presents some interesting features compared with the other water loadings. Aside from the intensity increase of the main peak around $Q=1.7 \AA^{-1}$, on cooling the sample to $200 \mathrm{~K}$, the scattered intensity shows the appearance of narrow and sharp peaks at 1.61 and $1.71 \AA^{-1}$, with a weaker-intensity shoulder at $1.82 \AA^{-1}$ (see the inset of Fig. 1). Moreover, three more narrow peaks appear at 2.8, 3.02 and $3.28 \AA^{-1}$, characteristic of crystalline water. These peaks have already been observed in a neutron diffraction study of water confined in a nanoporous silica matrix MCM-41 (Kamitakahara et al., 2012). Since it has been shown that the excess pore water crystallizes at temperatures around $260 \mathrm{~K}$ (Findenegg et al., 2008), the appearance of these peaks reveals the crystallization of a significant fraction of confined water.

The scattered intensity of the wetted $92 \mathrm{~S} 6$ samples contains the information on $\mathrm{SiO}_{2}-\mathrm{SiO}_{2}, \mathrm{H}_{2} \mathrm{O}-\mathrm{H}_{2} \mathrm{O}$ and $\mathrm{H}_{2} \mathrm{O}-\mathrm{SiO}_{2}$ pairs, whereas the intensity of the dry sample contains only the information on the $\mathrm{SiO}_{2}-\mathrm{SiO}_{2}$ pairs. Therefore, the contribution of water is obtained by subtracting the intensity of the dry sample from that of the wet sample (Hsieh et al., 2013):

$$
I=I_{\text {Wet sample }}-I_{\text {Dry sample }}=I_{\mathrm{H}_{2} \mathrm{O}-\mathrm{H}_{2} \mathrm{O}}+I_{\mathrm{H}_{2} \mathrm{O}-\mathrm{SiO}_{2}} \text {. }
$$

The obtained data were corrected for absorption, polarization and multiple scattering using the program PDFgetX2 (Qiu et al., 2004).

The total scattering structure function $S(Q)$ of the sample was obtained by normalizing the measured scattering intensity by the average scattering factor over all atoms and the total number of scattering centres in the sample. The PDF $G(r)$ was then obtained by the sine Fourier transform of the reduced total scattering factor $F(Q)=Q[S(Q)-1]$ (Proffen et al., 2003),

$$
G(r)=\frac{2}{\pi} \int_{0}^{\infty} Q[S(Q)-1] \sin (Q r) \mathrm{d} Q .
$$

In order to calculate the experimental PDF, data were integrated and truncated at a finite maximum value of $Q_{\max }=$ $15.5 \AA^{-1}$ beyond which the signal-to-noise ratio became unfavourable.

\subsection{EPSR simulation}

The local description of interatomic pair correlations can be achieved using the Empirical Potential Structure Refinement (EPSR) code (Soper, 1996, 2001), which is a Monte Carlo 
algorithm in which pair potentials are empirically refined against the experimental X-ray scattering data. Mancinelli and co-workers (Mancinelli et al., 2009) studied the structural properties of water confined in MCM-41 using such a multiscale approach with the EPSR software. They mentioned that every sample might exhibit quite distinct characteristics depending on the synthesis procedure. Therefore, an appropriate simulation box has to be built for each sample according to its components.

Bchellaoui et al. (2017) studied the characteristics of $92 \mathrm{~S} 6$ and showed that the massless pores occupy a specific volume: $V_{\text {pores }}=0.76 \mathrm{~cm}^{3} \mathrm{~g}^{-1}$. So, $1 \mathrm{~g}$ of silica corresponds to a volume of $V_{\mathrm{SiO} 2}=1 / \rho_{\mathrm{SiO} 2}=0.45 \mathrm{~cm}^{3} \mathrm{~g}^{-1}$, where $\rho_{\mathrm{SiO} 2}=2.2 \mathrm{~g} \mathrm{~cm}^{-3}$ is the mass density of the silica without considering the pores (local density). Thus, the global volume occupied by silica and pores should be: $V_{\mathrm{SiO} 2}+V_{\text {pores }}=1.21 \mathrm{~cm}^{3} \mathrm{~g}^{-1}$. This volume correlates with an average density of $\rho_{\text {grain }}=1 / 1.21=$ $0.826 \mathrm{~g} \mathrm{~cm}^{-3}$.

So, one should consider two distinct densities for the sample: the local density and the average density, depending on whether the pore volume is considered or not. In our model, the local density $\rho_{1}=2.2 \mathrm{~g} \mathrm{~cm}^{-3}$ was used for the calculation of the number of atoms to insert in the simulation box. This density corresponds to 0.0662 atoms $\AA^{-3}$.

Confined water has a density of 0.086 atoms $\AA^{-3}$ compared with 0.1 atoms $\AA^{-3}$ for bulk water (Mancinelli et al., 2009).

The model consists of building a cuboid box of height $h$ with a single centred cylindrical pore of radius $r$ inside. The size of the box was obtained by calculating the matrix/pore volume ratio as follows using the experimental local density and pore volume (Mancinelli et al., 2009):

$$
V_{\text {box }} / V_{\text {pores }}=\left[\left(1 / \rho_{1}\right)+V_{\text {pores }}\right] / V_{\text {pores }}=L^{2} / \pi r^{2}
$$

where, in the simulation box, $V_{\text {total }}=V_{\text {box }}=L^{2} h$, and $V_{\text {pores }}=$ $\pi r^{2} h$.

In the sample, $V_{\text {total }}=\left(1 / \rho_{1}\right)+V_{\text {pores }}$ and $V_{\text {pores }}=$ $0.76 \mathrm{~cm}^{3} \mathrm{~g}^{-1}$.

Using these equations, one calculates the size of the simulation box, $L$ :

$$
L=r\left(\pi\left\{1+\left[1 /\left(\rho_{1} V_{\text {pores }}\right)\right]\right\}\right)^{1 / 2} .
$$

For $r=28 \AA, \rho_{1}=2.2 \mathrm{~g} \mathrm{~cm}^{-3}$ and $V_{\text {pores }}=0.76 \mathrm{~cm}^{3} \mathrm{~g}^{-1}$, one obtains a box size value of $L=63 \AA$. The height of the box, $h$, was chosen to be $42 \AA$.

2.5.1. Dry sample modelling. In order to build the simulation box, we proceeded in the following steps. Firstly, Si and O atoms were filled in the cuboid box according to the local density. Secondly, a cylinder with a specific radius was drilled in the middle of the box by removing the atoms lying within a distance $r$ from the $z$ axis. The radius was chosen based on the 9256 pore diameter. We further defined silanol groups, $\mathrm{Ca}$ and $\mathrm{P}$ at the surface of the pores. The presence of silanol groups at the surface gives the sample its hydrophilic character. The 92S6 pore size distribution was calculated from adsorption isotherms and presents a maximum at a pore diameter of $5.9 \mathrm{~nm}$ (Bchellaoui et al., 2017). Thirdly, the internal pore

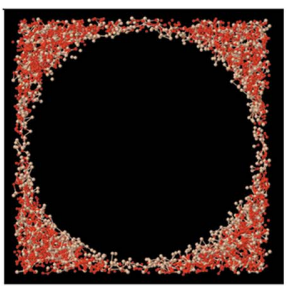

$\mathrm{SiO}_{2}$

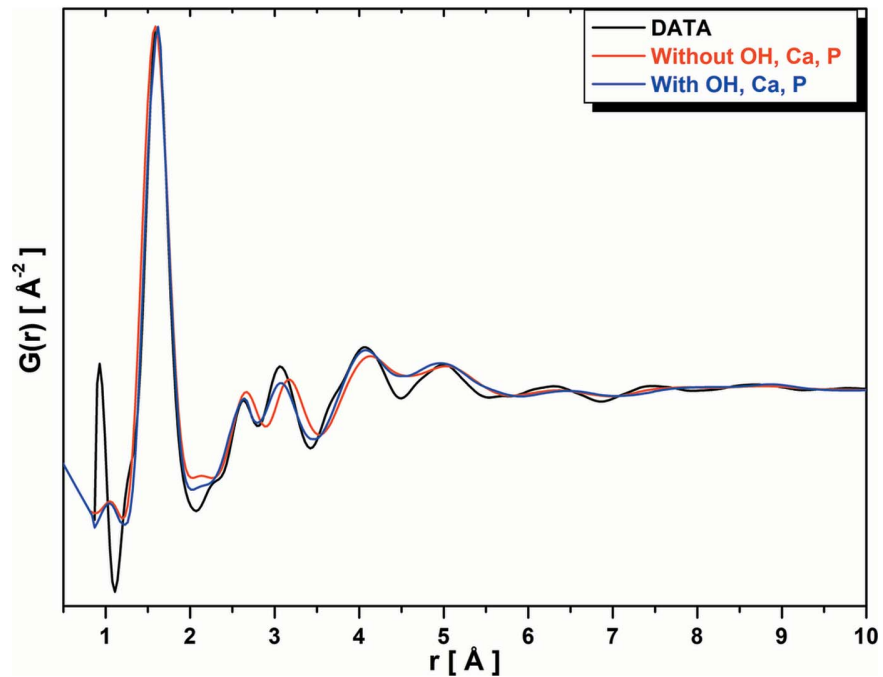

Figure 2

Top: snapshots representing the silica structure before and after decorating the pore with $\mathrm{OH}$ groups, $\mathrm{Ca}$ and P. Bottom: total PDF, $G(r)$, for the dry $92 \mathrm{~S} 6$ sample. In black: the experimental PDF. In red: the simulated PDF without taking into account the $\mathrm{OH}$ groups, $\mathrm{Ca}$ and $\mathrm{P}$. In blue: the simulated PDF with the $\mathrm{OH}$ groups, $\mathrm{Ca}$ and $\mathrm{P}$.

surface was decorated by silanol groups, Ca and P (see Fig. 2 top). Note that the insertion of $\mathrm{Ca}, \mathrm{P}$ and $\mathrm{OH}$ groups in the inner surface of the pores provides reliable results compared with the experimental data, as can be seen from the comparison of the corresponding PDFs (see Fig. 2 bottom). Taking into account the contributions of $\mathrm{OH}$ groups, $\mathrm{Ca}$ and $\mathrm{P}$ significantly improves the agreement between the experimental and simulated PDFs.

It is well known that the existence of calcium and phosphorus in bioactive glasses has a positive effect on the bioactivity. Calcium is a so-called modifier cation, which influences the silicate network by replacing $\mathrm{Si}-\mathrm{O}-\mathrm{Si}$ bonds with $\mathrm{Si}-\mathrm{nbO}$ (nbO: nonbridging oxygen) (Tilocca, 2009), and as a consequence ionic bonds between nbO atoms and calcium cations $\mathrm{Ca}^{2+}$ will form. These bonds are crucial for the glass stability and the charge neutrality of the system. On the other hand, phosphorus forms $\mathrm{Si}-\mathrm{O}-\mathrm{P}$ bonds. It has been shown that, in sol-gel glasses, phosphorus slows down the initial reactivity, but accelerates the HCA formation rate (Salinas et al., 2002). Other studies show that phosphorus has two opposite side effects on the bioactivity depending on the $\mathrm{P}_{2} \mathrm{O}_{5}$ fractions. They demonstrate that the positive effect prevails for low $\mathrm{P}_{2} \mathrm{O}_{5}$ fractions $(<10 \%)$ by improving the bioactivity, while a substantial fraction of $\mathrm{P}_{2} \mathrm{O}_{5}$ has a negative effect by reducing the bioactivity (Tilocca et al., 2007). This fact has 
Table 1

Atomic composition used in the simulation box.

\begin{tabular}{llllllll}
\hline Component & $\mathrm{Si}$ & $\mathrm{bO}$ & $\mathrm{Sil}$ & $\mathrm{nbO}$ & $\mathrm{H}$ & $\mathrm{Ca}$ & $\mathrm{P}$ \\
\hline Number & 1280 & 2721 & 103 & 185 & 103 & 21 & 60 \\
\hline
\end{tabular}

been explained by Lusvardi et al. (2008) who postulated that the formation of $\mathrm{Si}-\mathrm{O}-\mathrm{P}$ links removes the $\mathrm{Ca}$ and $\mathrm{Na}$ from the silicate network of bioactive glasses.

The coordination number of silicon atoms within $0.9 \AA$ of the pore surface was calculated. Any silicon atom with a coordination number equal to three was termed Sil, and an $\mathrm{OH}$ group was added at a distance of $1.6 \AA$. Then, the coordination number of oxygen atoms within $0.9 \AA$ of the pore surface was calculated. Any oxygen atom with a coordination number equal to two was termed 'bridging oxygen' (bO). If the coordination number of oxygen atoms was one, the atom was termed nbO. The number of nbO atoms within $0.9 \AA$ of the pore surface was calculated; then, a part of these atoms was bonded to a phosphorus atom and the remaining nbO atoms were saturated by including calcium cations $\mathrm{Ca}^{2+}$. The ratios of $\mathrm{Ca}$ and $\mathrm{P}$ were chosen based on the sample composition.

Finally, the pore radius was modified until a best fit with the experimental data was obtained. This resulted in a pore radius of $28 \AA$. The final atomic composition for the simulation box is reported in Table 1 .

2.5.2. Setting the reference potential. At this stage, the Monte Carlo routine with a reference interaction potential between atomic sites will be running. The starting point in an EPSR simulation is to define the reference potential parameters of each component of the structure.

The reference potential is based on a Lennard-Jones 12-6 potential plus effective Coulomb charges (Bowron, 2008):

$$
U_{\alpha \beta}\left(r_{i j}\right)=4 \epsilon_{\alpha \beta}\left[\left(\frac{\sigma_{\alpha \beta}}{r_{i j}}\right)^{12}-\left(\frac{\sigma_{\alpha \beta}}{r_{i j}}\right)^{6}\right]+\frac{q_{\alpha} q_{\beta}}{4 \pi \epsilon_{0} r_{i j}}
$$

where $r_{i j}$ is the distance between atoms $i$ and $j ; q_{\alpha}$ and $q_{\beta}$ are the charges of atoms $\alpha$ and $\beta$, respectively.

When the types of the two atoms are different $(\alpha$ and $\beta)$, the well depth parameter $\epsilon_{\alpha \beta}$ (in EPSR measured in $\mathrm{kJ} \mathrm{mol}^{-1}$ ) and the range parameter $\sigma_{\alpha \beta}$ (in EPSR measured in $\AA$ ) are given by the usual Lorentz-Berthelot mixing rules (Allen \&

\section{Interfacial: $30 \%$}

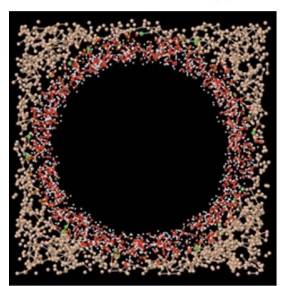

Intermediate: $60-30 \%$

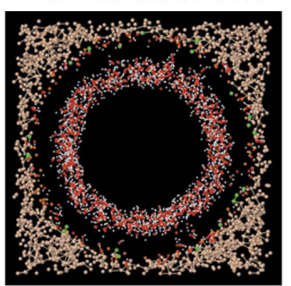

Centred: $100-60 \%$

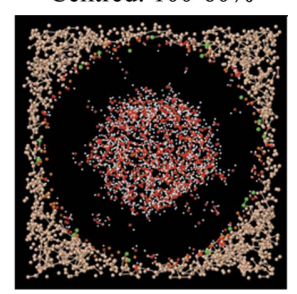

Figure 3

Snapshots representing the simulated structure for the different species of confined water. Left: interfacial pore water; middle: intermediate pore water; right: centred pore water. Oxygen atoms were removed from the silica for clarity.
Table 2

Lennard-Jones potential parameters and charges used for 92S6 and confined water.

\begin{tabular}{llll}
\hline Atom type & $\epsilon\left(\mathrm{kJ} \mathrm{mol}^{-1}\right)$ & $\sigma(\AA)$ & Charge (e) \\
\hline $\mathrm{Si}$ & 0.80 & 0.76 & 4 \\
bO & 0.65 & 3.69 & -2 \\
$\mathrm{Sil}$ & 0.80 & 0.76 & 4 \\
$\mathrm{nbO}$ & 0.65 & 3.69 & -2 \\
$\mathrm{H}$ & 0.0 & 0.0 & 1 \\
$\mathrm{P}$ & 0.51 & 2.15 & 2.25 \\
$\mathrm{Ca}$ & 0.175 & 2.63 & 2 \\
$\mathrm{O}_{\mathrm{w}}$ & 0.65 & 3.166 & -0.8476 \\
$\mathrm{H}_{\mathrm{w}}$ & 0.00 & 0.00 & 0.4238 \\
\hline
\end{tabular}

Tildesley, 1987) in terms of their values for the individual atoms:

$$
\epsilon_{\alpha \beta}=\left(\epsilon_{\alpha} \epsilon_{\beta}\right)^{1 / 2} ; \sigma_{\alpha \beta}=\frac{1}{2}\left(\sigma_{\alpha}+\sigma_{\beta}\right) .
$$

The reference potential parameters and the charges used in our simulation are listed in Table 2. For silica, silanol groups and confined water, $\sigma$ and $\epsilon$ values were chosen based on existing values in the literature (Mancinelli et al., 2009; Thompson et al., 2007).

The Lennard-Jones (LJ) potential parameters for Ca were chosen based on a previous study for building a Monte Carlo model for glasses (Bowron, 2014). In addition, the LJ potential parameters for $\mathrm{P}$ were taken from a molecular dynamics simulation study based on the structural analysis of binary phosphate glass with high calcium content (Karakassides et al., 2004).

2.5.3. Wetted samples modelling. After reaching a good fit to the experimental data for the dry sample, wetted samples were modelled by confining an appropriate number of water molecules inside the pores. Based on the experimental measurements, three samples with three water loadings, $30 \% 92 \mathrm{~S} 6,60 \% 92 \mathrm{~S} 6$ and $100 \% 92 \mathrm{~S} 6$, were modelled. The number of water molecules was calculated according to the volume ratio between confined water and the pore. An accurate analysis of the confined water defined by a cylindrical layers' description was required for studying the three different water loadings. This analysis consists of decomposing the confined water in three cylindrical areas.

For 30\%92S6, a cylindrical layer with $4 \AA$ thickness from the pore wall filled by water molecules was introduced inside the pore. The confined water density used is 0.086 atoms $\AA^{-3}$. For modelling $60 \% 92 \mathrm{~S} 6$, the number of water molecules was duplicated by maintaining constant density. In consequence, the existing water molecules from the first layer were surrounded by a second cylindrical layer with $7 \AA$ thickness. Finally, for $100 \% 92 S 6$, the pore was completely filled with water molecules by adding a cylinder of water molecules in the residual empty space inside the pore (see Fig. 3).

Once the box is built, it will be equilibrated in a configuration of minimum energy by running the Monte Carlo routine with the reference interaction potential. When getting the minimum energy, EPSR starts refining the potential and the configuration against experimental data. 


\section{Results and discussion}

\subsection{Experimental results: total $X$-ray scattering}

3.1.1. Room-temperature PDF. Fig. 4 shows the differential PDFs (d-PDFs) of water confined in 30\%92S6, 60\%92S6 and $100 \% 92$ S6. For comparison, the PDF of bulk water is shown, which exhibits two main peaks at 2.8 and $4.5 \AA$ A corresponding to the distances of the first and second $\mathrm{O}_{\mathrm{w}}-\mathrm{O}_{\mathrm{w}}$ neighbours, respectively. The peak at $4.5 \AA$ is broad with indication of an additional peak around $4.1 \AA$. These results are in agreement with the literature, describing the tetrahedral-like bulk-water local structure with characteristic distances at 2.85, 4.1 and $4.6 \AA$ (Smirnov et al., 2000; Yamanaka et al., 1994).

As can be seen in Fig. 4, the distances to the first neighbours are not affected by confinement. The first maximum at $2.8 \AA$ appears on all d-PDFs, independent of the amount of water loading, but it is wider for $30 \% 92 \mathrm{~S} 6$. This feature has already been observed for water confined in mesoporous MCM-41 silica, where it was shown that for low water contents, the distance distribution between the first neighbours becomes very broad compared with higher water contents (Smirnov et al., 2000). This finding was explained by the presence of interactions between the interfacial pore water and the silica at the surface of the pore. Moreover, the ratio of the interfacial pore water to the internal pore water is higher for $30 \% 92$ S6 than for $60 \% 92$ S6 and $100 \% 92$ S6.

The structure of water in 30\%92S6 exhibits significant differences with respect to the bulk structure. The first neighbours are localized at $2.8 \AA$ as in bulk water, but the second neighbours are distributed on two sites at 4 and $4.9 \AA$ compared with bulk water in which a single peak at $4.5 \AA$ is found. These findings give evidence for the distortion of the tetrahedral-like hydrogen-bonded network for low water loading, either due to the effective change of the geometrical structure of confined water and/or due to the interactions with the silica. Similar findings were reported by Soper and coworkers (Bruni et al., 1998), who studied the PDF for water

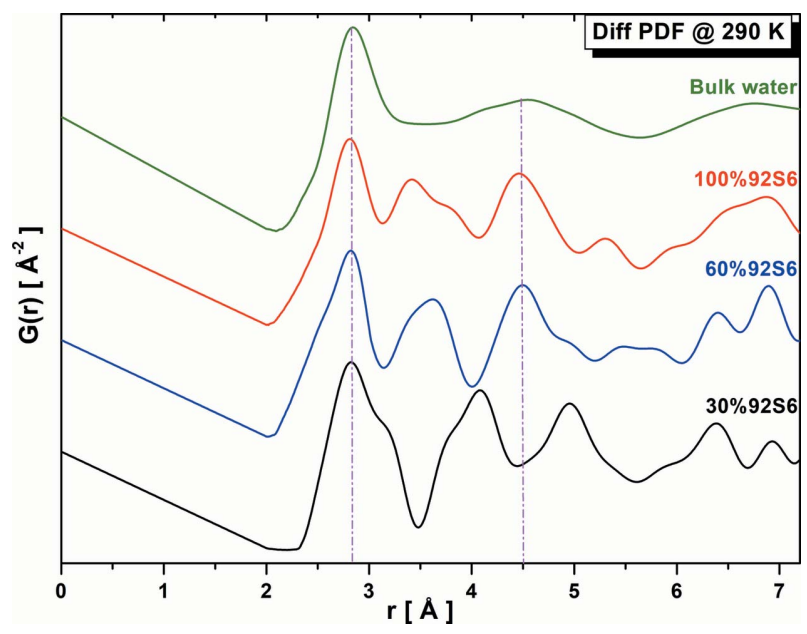

Figure 4

Differential X-ray pair distribution functions, d-PDFs, of water confined in $30 \% 92 \mathrm{~S} 6,60 \% 92 \mathrm{~S} 6$ and $100 \% 92 \mathrm{~S} 6$ compared with that of bulk water at $290 \mathrm{~K}$. Vertical lines indicate positions at 2.8 and $4.5 \AA$. confined in Vycor, for which they found a pair correlation at $4 \AA$ between oxygen atoms which becomes more pronounced at low water loadings. Fouzri et al. (2002) also studied the pair correlation function of the confined water in silica gel wetted at $20 \mathrm{wt} \%$, and their d-PDFs are in very good agreement with the d-PDF of $30 \% 92 \mathrm{~S} 6$.

For water in $60 \% 92 \mathrm{~S} 6$, the second neighbours are localized at $4.5 \AA$ accompanied by a shoulder at $4.9 \AA$. The peak at $4.5 \AA$ is narrower than for bulk water. These results suggest that the tetrahedral-like water structure is present in this sample and it is less distorted than in 30\%92S6. Increasing the water loading to $100 \%$, the d-PDF shows the second neighbours at the same distances compared with the bulk water at $4.5 \AA$, but again this peak is narrower than for bulk water. XRD data for water confined in silica gel were collected at room temperature for different water loading by Fouzri and co-workers (Fouzri et al., 2001). Our observations are fully consistent with their results, where they have shown that for low water loading, the second neighbours of the confined water are distributed on two sites, 3.9 and $4.8 \AA$. Moreover, when the water loading is increased to $50 \mathrm{wt} \%$, the second neighbours were found at $4.5 \AA$. Smirnov and co-workers (Smirnov et al., 2000) have also performed X-ray scattering measurements for water confined in MCM-41 samples with different pore diameters, $\mathrm{C} 10(d=21 \AA)$ and $\mathrm{C} 14(d=28 \AA)$. The X-ray PDF for the $\mathrm{C} 14$ capillary condensed water shows three main peaks at $2.84,4.08$ and $4.85 \AA$. In comparison with our results, this d-PDF is very similar to the d-PDF of the sample with low water loading. This fact might be explained by the pore size difference between our sample and C14 in which the water layer grows axially in the direction of the pore axis, whereas for samples such as ours, it grows radially towards the pore centre (Grünberg et al., 2004). These results indicate that by decreasing the amount of confined water, its structure becomes more distorted, most probably due to the dominance of the silica-bonded water compared with the free pore water.

Two additional pair correlations, localized at $\sim 3.3$ and $\sim 3.75 \AA$, appear on the d-PDF of the confined water. The d-PDFs show that the position of the peak at $\sim 3.3 \AA$ changes with the water loading (3.2 $\AA$ for $30 \% 92$ S6, $3.4 \AA$ for $60 \% 92$ S6 and $100 \% 92$ S6). This difference may be explained by the fact that the structuring of the different layers of water can be affected by the amount of water loading. Indeed, it is well established that, as the degree of confinement is increased to prevent freezing, the water becomes progressively less bulklike, and water-substrate interactions start to influence both the structure dynamics and thermodynamic properties. Thus, the structure of water in the pores is correlated to the number of the water layers within the silica nanopores. In the case of $30 \%$ 92S6, most of the loaded water is directly interacting with the silica pore walls and thus forms a layer with a thickness of $\sim 4 \AA$. This layer is considered as non-freezable pore water and has a distorted structure. However, the situation is different in the case of $60 \% 92$ S6 and 100\% 92S6. The interfacial layer is covered by other layers which generates additional $\mathrm{O}_{\mathrm{w}}-\mathrm{O}_{\mathrm{w}}$ interactions that certainly influence the structural organization of the first interfacial layer. Similar 
correlation has been observed in the literature at different distances depending on the water loading and the pore diameter of the measured material. Smirnov et al. (2000) showed that confined water in MCM-41 presents a pair correlation at a distance of $3.3 \AA$, which was attributed to the
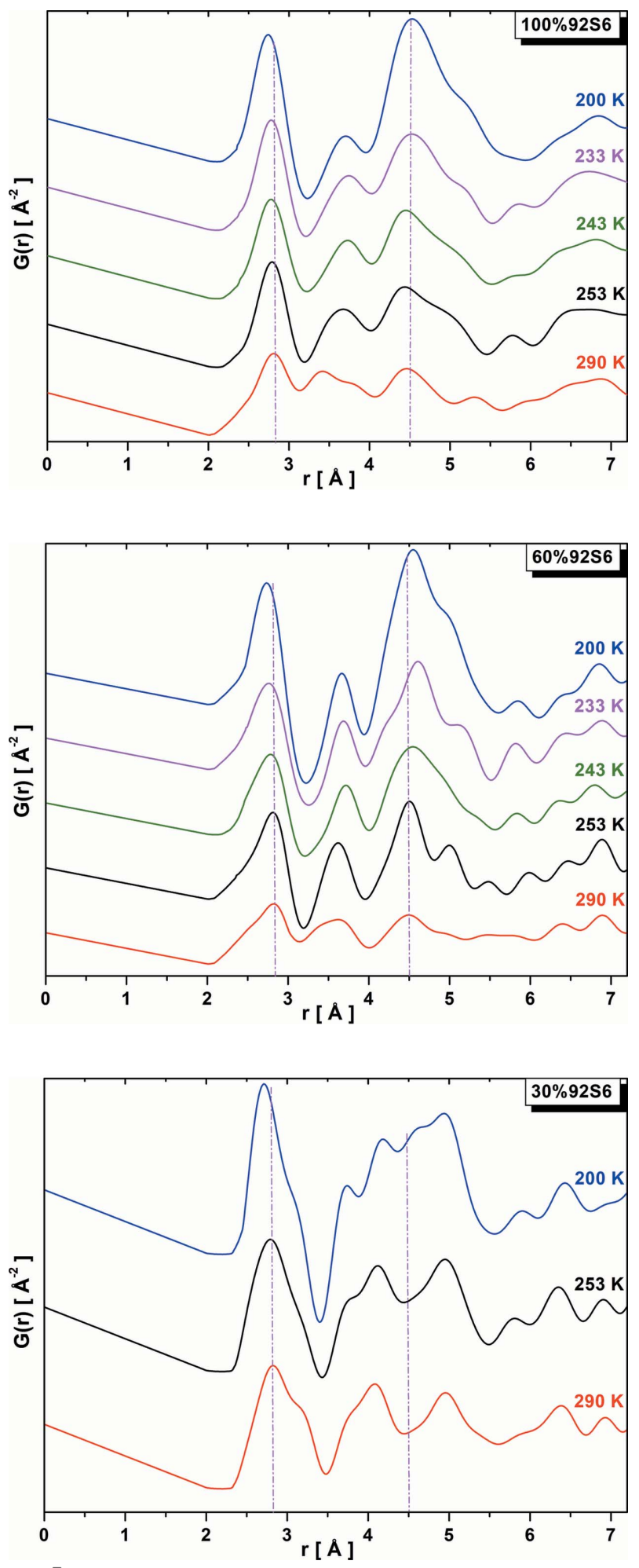

Figure 5

Variable-temperature differential X-ray pair distribution functions, d-PDFs, of water confined in: 100\%92S6 (top), 60\%92S6 (middle), $30 \% 92 \mathrm{~S} 6$ (bottom). Vertical lines indicate positions at 2.8 and $4.5 \AA$. so-called non-hydrogen-bonded water. Yamanaka et al. (1994) studied the d-PDF of water at different temperatures. They found that the tetrahedral-like network for water molecules is characterized by hydrogen-bonded water with pair correlations at $2.85,4.1$ and $4.6 \AA$, and an additional pair correlation at $3.4 \AA$, which was attributed to $\mathrm{O}_{\mathrm{w}}-\mathrm{O}_{\mathrm{w}}$ distances between non-hydrogen-bonded water molecules.

The peak at $3.75 \AA$ is located at the same distance for all water loadings. Smirnov et al. found a pair correlation at $3.8 \AA$ for water confined in mesoporous MCM-41; this peak was attributed to the $\mathrm{O}_{\mathrm{w}}-\mathrm{Si}$ pair correlations between the interfacial pore water and the silica at the pore surface (Smirnov $e t$ al., 2000). These pair correlations have been neglected by some authors (Bellissent-Funel et al., 1993, 1996), while other authors (Soper et al., 1998) claim that they should not be neglected. According to these latter studies, this distance might designate the $\mathrm{O}_{\mathrm{w}}-\mathrm{Si}$ pair correlations between confined water and the hydroxylated silica at the pore wall.

3.1.2. Variable-temperature PDF. In order to affirm the attribution of these peaks, we investigated them by studying the structure as a function of temperature using total X-ray scattering coupled to PDF analysis. Fig. 5 shows the d-PDFs of water in $100 \% 92 \mathrm{~S} 6$ (top) and $60 \% 92 \mathrm{~S} 6$ (middle), at 290, 253, 243,233 and $200 \mathrm{~K}$. The d-PDFs of water in $30 \% 92 \mathrm{~S} 6$ (bottom) are also shown at 290, 253 and $200 \mathrm{~K}$.

For water in $60 \% 92 \mathrm{~S} 6$ and $100 \% 92 \mathrm{~S} 6$, the d-PDF diagrams show that, with decreasing temperature, the peak intensities of the first and second neighbours' pair correlations at 2.8 and $4.5 \AA$ increase, accompanied by a shift of the first neighbours to shorter distances, $2.71 \AA$. This finding has been observed by Smirnov et al. (2000) for water confined in MCM-41. The peak at $3.75 \AA$ is not strongly affected by the temperature, as shown in Fig. 5. In contrast, the peak intensity at $3.4 \AA$ decreases gradually with decreasing temperature. At $200 \mathrm{~K}$, this peak disappears completely, indicating that non-hydrogen-bonded water diminishes with decreasing temperature, converting into hydrogen-bonded water.

For water in $30 \% 92 \mathrm{~S} 6$, the intensities of the d-PDF peaks exhibit fewer changes with temperature compared with the 60 and $100 \%$ loading samples. This observation is consistent with previous studies (Findenegg et al., 2008; Schreiber et al., 2001; Rennie \& Clifford, 1977), where it was reported that the first two monolayers of the confined water with a thickness of 3-5 $\AA$ around the pore wall are ascribed as non-freezable pore water. It has been reported from a neutron diffraction study that a strong correlation between water molecules and hydroxyl groups exists in the pore surface vicinity (Takamuku et al., 1997). Soper $(2013,2012)$ has shown that the water confined in MCM-41 adopts almost a low-density form (LDW) even in the core region of the nanopore, and that on cooling to $210 \mathrm{~K}$, the confined water has a more tetrahedral order in the liquid compared with bulk water.

At low temperature, $200 \mathrm{~K}$, the first peak on the d-PDF of $30 \% 92 \mathrm{~S} 6$ exhibits a shoulder at $3.2 \AA$, indicative of an important interaction between the interfacial confined water and the silica pore walls, leading to a structural distortion in the tetrahedral-like water network. In a molecular dynamics 
simulation study, Lee \& Rossky (1994) showed that a decrease in the $\mathrm{O}_{\mathrm{w}}-\mathrm{O}_{\mathrm{w}}$ pair correlations is observed near the hydroxyl group at the pore surface. It was also mentioned that such a decrease is compensated by the interactions between the pore surface and the interfacial water. Since the freezing properties of confined water change with increasing water loading, this pair correlation might serve as an indicator of the non-freezing water structure.

The total X-ray scattering measurements and the derived d-PDFs clearly indicate the existence of different structural organizations of confined water in the pores of bioactive glasses and that this structural organization depends strongly on the amount of water loading. Moreover, the closer the water molecules are to the pore surface, the more distorted is the structure of the network.

\subsection{EPSR results}

In order to gain more insight into these structural deformations and to propose a structural model explaining the main observations for the water confined in 92S6, we present in the following results that we obtained using the EPSR code, which allow for refinement against the experimental data (see Section 2.4). In particular, we will analyse the site-site partial PDF of the different structural organizations of confined water.

3.2.1. Model versus experiment. In order to calculate the PDF of bulk water and compare it with the experimental PDF, a cubic box filled with water molecules was created. Bulk water has a density of 0.1 atom $\AA^{-3}$, higher than that of confined water. Experimental and calculated PDFs for bulk water are shown in Fig. 6.

The simulated PDF is in good agreement with the experimental one. Three main peaks appear at 2.8, 4.5 and $6.9 \AA$ corresponding to the $\mathrm{O}_{\mathrm{w}}-\mathrm{O}_{\mathrm{w}}$ first, second and third neighbours, respectively.

Fig. 7 shows the comparison between the simulated and the measured $F(Q)$ and $G(r)$ of the studied samples. One can

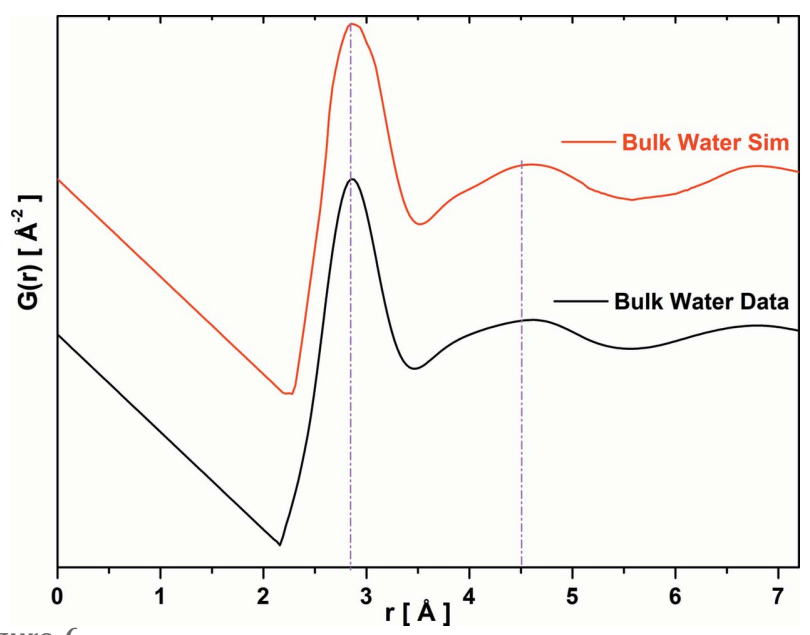

Figure 6

Total PDF for bulk water: experimental (black) versus simulated with $\operatorname{EPSR}$ (red). Vertical lines indicate positions at 2.8 and $4.5 \AA$. observe a good agreement between the simulated and the experimental results. The $G(r)$ shows that the $\mathrm{Si}-\mathrm{O}$ and the $\mathrm{O}-$ O pair correlations, typical of amorphous silica, are located at 1.6 and $2.6 \AA$, respectively. Moreover, the EPSR fitted to the reduced structure factor of the experimental data $F(Q)$ reproduces the different peak amplitudes reasonably well, albeit with some discrepancies. Soper (2013) has clarified the sensitivity of such an EPSR method for fitting the experimental data, and mentioned that models within EPSR assume a perfect sample without any deformation and deficiency while significant defects are present in the real material, which could be responsible for such discrepancies in the fit to the data.

Furthermore, in order to enable a detailed comparison between experiment and simulation with respect to the structural signatures of the confined water, the simulated d-PDFs have been calculated following the same procedure used for the experimental d-PDFs. Fig. 8 shows the obtained results for the three modelled water loadings, 30\%92S6, $60 \% 92 \mathrm{~S} 6$, and $100 \% 92 \mathrm{~S} 6$. We observed that the simulated d-PDFs are in good agreement with the experimental d-PDFs (compare Fig. 8 and Fig. 4). Indeed, the pair correlations are
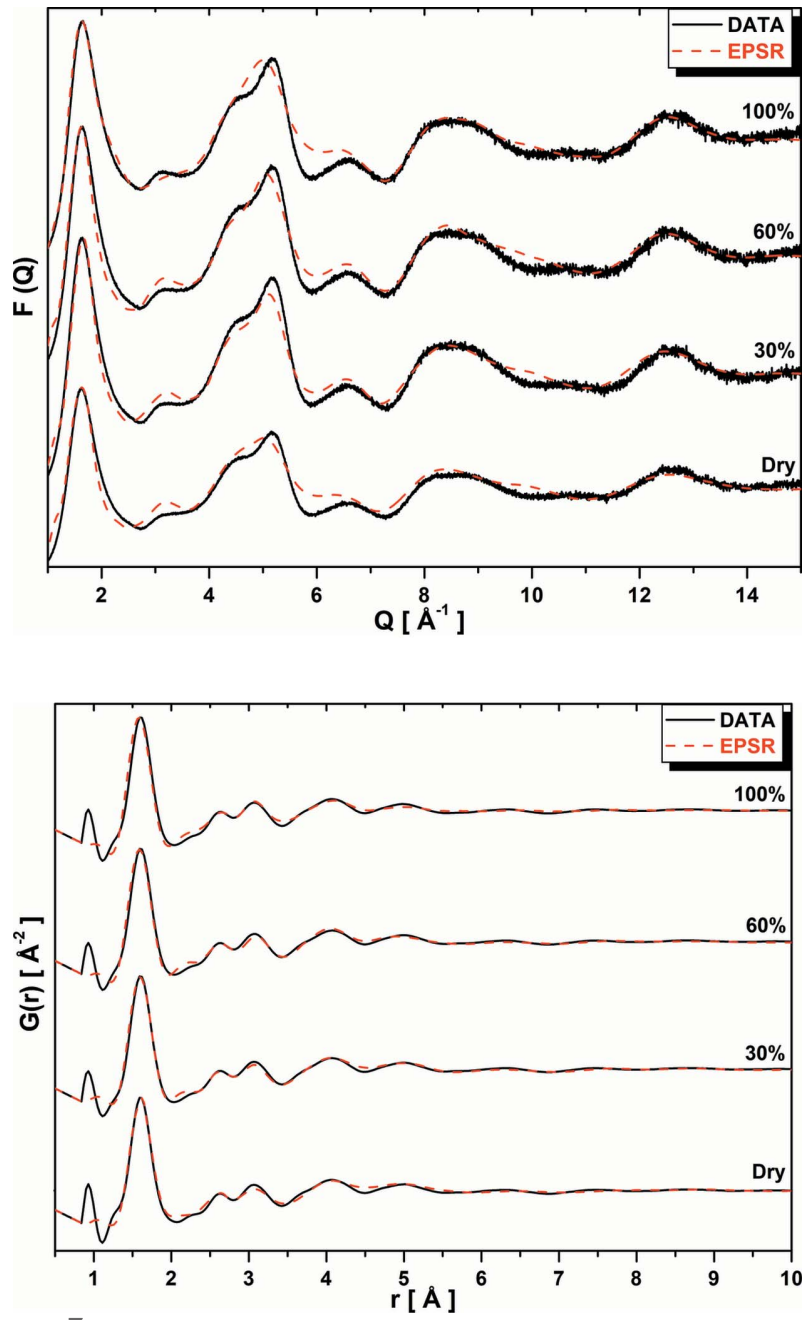

Figure 7

EPSR fit to the data for the dry and hydrated 92S6 sample. Top: reduced total structure factor $F(Q)$; bottom: total PDF $G(r)$. Experimental (black line) versus simulated with EPSR (dashed red line). 


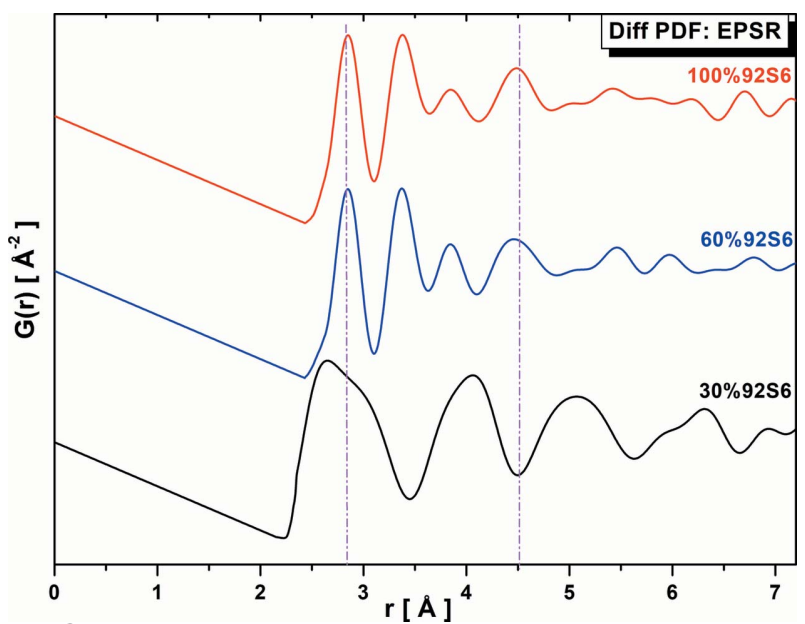

Figure 8

Differential pair distribution functions, d-PDFs, of water confined in 92S6 with the three water loadings $(30 \%, 60 \%, 100 \%)$ calculated from the sine Fourier transform of the subtracted structure factor between dry and wet modelled samples. Vertical lines indicate positions at 2.8 and $4.5 \AA$.

found at the same distances in the simulated and the experimental d-PDFs. These results indicate the reliability of the model we used in this study. Therefore, one can proceed to the calculation and the analysis of the site-site partial PDF, which allows for a detailed interpretation of the relevant pair correlations in the studied materials.

3.2.2. Cross-correlation terms. EPSR provides the distribution between any pairs of atoms. Therefore, it allows the calculation of the partial PDF between the confined water and the silica gel. The results obtained for the $92 \mathrm{~S} 6$ with the three water loadings are shown in Fig. 9. For all the samples, the $\mathrm{O}_{\mathrm{w}}-$ Si pair correlation occurs at $\sim 3.75 \AA$, indicating that adding the second and the third layers does not affect significantly the water-substrate interactions.

The experimental d-PDF of the confined water (see Fig. 4) exhibits an additional peak at $3.75 \AA$ compared with the bulk water, independent from the amount of water loading. Thus, our simulation gives strong evidence that the pair correlation between the water molecules and the silica at the pore wall contributes to this peak.

3.2.3. $\mathrm{O}_{\mathrm{w}}-\mathrm{O}_{\mathrm{w}}$ partial PDF. In the following, we concentrate on the analysis of the pair correlation between confined water molecules. Fig. 10 shows the $\mathrm{O}_{\mathrm{w}}-\mathrm{O}_{\mathrm{w}}$ partial PDFs of confined water with different water loadings obtained from our simulations.

For all water loadings, water confined in the first cylindrical area (hereafter called interfacial pore water) exhibits the same $\mathrm{O}_{\mathrm{w}}-\mathrm{O}_{\mathrm{w}}$ partial PDF. It shows peaks in good agreement with the experimental d-PDF for 30\%92S6. First neighbours are localized at $2.8 \AA$ as bulk water, while second neighbours are affected by the distortion of the network, and are distributed on two sites localized at 4.1 and $4.9 \AA$. A less intense peak appears at $3.3 \AA$, which was attributed by some authors (Smirnov et al., 2000; Yamanaka et al., 1994) to the nonhydrogen-bonded water-water pair correlations.

For $60 \% 92 \mathrm{~S} 6$ and $100 \% 92 \mathrm{~S} 6, \mathrm{O}_{\mathrm{w}}-\mathrm{O}_{\mathrm{w}}$ partial PDFs of water in the second regions (hereafter called intermediate pore

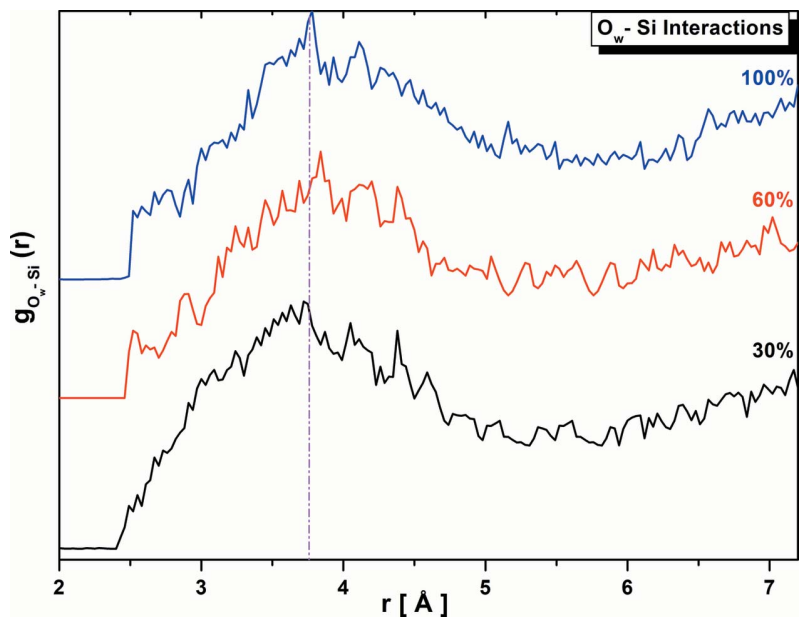

Figure 9

$\mathrm{O}_{\mathrm{w}}-\mathrm{Si}$ partial PDFs as calculated by EPSR for $30 \% 92 \mathrm{~S} 6,60 \% 92 \mathrm{~S} 6$, $100 \% 92 \mathrm{~S} 6$. The vertical line indicates the position at $3.75 \AA$.

water) present the same characteristics. Unlike the interfacial pore water, two peaks for the second neighbours appear at 3.65 and $4.5 \AA$, while the additional peak at $3.3 \AA$ found in interfacial pore water disappears from the $\mathrm{O}_{w}-\mathrm{O}_{\mathrm{w}}$ partial PDF of intermediate pore water. This result shows that the correlation at $3.75 \AA$ found in the experimental d-PDF (see Fig. 4) may contain a contribution of the $\mathrm{O}_{\mathrm{w}}-\mathrm{O}_{\mathrm{w}}$ pair correlation along with the $\mathrm{O}_{\mathrm{w}}-\mathrm{Si}$ pair correlation. A molecular dynamics simulation of water confined in cylindrical $\mathrm{SiO}_{2}$ pores was studied by Rovere and co-workers (Rovere et al., 1998). They have shown that interactions between water and substrate atoms lead to the distortion of the hydrogen-bonded network. This finding is in agreement with our results, as the tetrahedral hydrogen-bonded network is less distorted in the intermediate pore water compared with the interfacial pore water, where a strong interaction exists between water and hydroxylated silica surfaces.

The $100 \% 92$ S6 holds a cylindrical region filled with water molecules at the centre of the pore (hereafter called centred pore water). Confined water in this region shows an $\mathrm{O}_{w}-\mathrm{O}_{w}$ partial PDF close to that of bulk water. Two main peaks appear at 2.8 and $4.5 \AA$ without any sign of distortion. Mancinelli and co-workers (Mancinelli et al., 2009) studied the partial PDF for water confined in MCM-41 using EPSR. They have shown that the structure of the interfacial water molecules is strongly distorted compared with the centred pore water and bulk water. Our investigations clearly show that confined water has a non-homogeneous structure with three different structural organizations depending on the distance from the pore wall and on the water loadings. The longer the distance is between water molecules and the pore wall, the weaker the water-silica interaction, resulting in a structure close to that of bulk water.

\section{Conclusions}

The performed temperature-dependent total X-ray scattering measurements coupled to PDF analysis have revealed the 

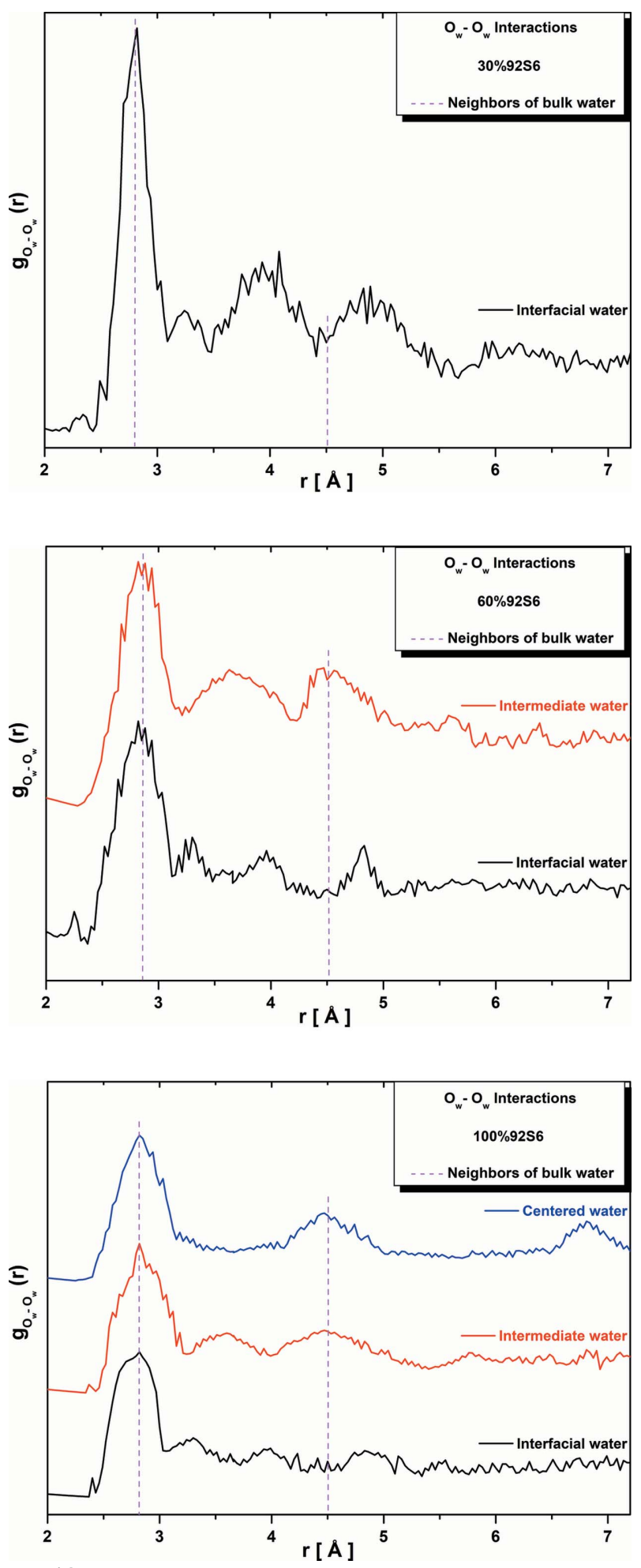

Figure 10

$\mathrm{O}_{\mathrm{w}}-\mathrm{O}_{\mathrm{w}}$ partial PDFs as calculated by EPSR for water in the cylindrical regions of the different water loadings. Interfacial for 30\%92S6 (top). Interfacial + intermediate pore water for $60 \% 92 \mathrm{~S} 6$ (middle). Interfacial + intermediate pore water + centred pore water for $100 \% 92 \mathrm{~S} 6$ (bottom). Vertical lines indicate positions at 2.8 and $4.5 \AA$.

significant pair correlations of water molecules confined in the bioactive glass $92 \mathrm{~S} 6$ for three samples with a different amount of water loading. EPSR simulations for all samples with respect to the experimental measurements allowed for the interpretation of the observations, especially via the analysis of the partial PDFs. In summary, the structure of the confined water can be described using three configurations, depending on the distance to the pore surface. In the first layer of about $4 \AA$ of so-called interfacial pore water, strong chemical bonds with the silica at the pore wall are formed, resulting in a distorted tetrahedral-like hydrogen-bonded network, characterized by $\mathrm{O}_{\mathrm{w}}-\mathrm{O}_{\mathrm{w}}$ second neighbour pair correlations at $\sim 4.1$ and $\sim 4.9 \AA$, as well as a further $\mathrm{O}_{\mathrm{w}}-\mathrm{O}_{\mathrm{w}}$ pair correlation at $3.2 \AA$ due to so-called non-hydrogen-bonded water. The $\mathrm{O}_{\mathrm{w}}-\mathrm{Si}$ pair correlation is found at $3.75 \AA$. In the second layer between 4 and $11 \AA$, named intermediate pore water, the structure is less distorted. The $\mathrm{O}_{\mathrm{w}}-\mathrm{O}_{\mathrm{w}}$ second neighbour pair correlations are found at $4.5 \AA$ like in bulk water. However, the presence of a further $\mathrm{O}_{\mathrm{w}}-\mathrm{O}_{\mathrm{w}}$ pair correlation at $3.65 \AA$ identified in the simulation indicates that the structure in this layer is still slightly distorted. The third layer with distances $>11 \AA$ from the pore wall corresponds to the water in the centre of the pore. Here, the $\mathrm{O}_{\mathrm{w}}-\mathrm{O}_{\mathrm{w}}$ pair correlations are the same as those in bulk water. Finally, we note that the pair correlation at $\sim 3.3 \AA$ (so-called non-hydrogen-bonded water) that appears on the d-PDFs of $60 \% 92 \mathrm{~S} 6$ and $100 \% 92 \mathrm{~S} 6$ at room temperature disappears when lowering the temperature to $200 \mathrm{~K}$. We note that this pair correlation is found at $3.2 \AA$ in the sample with the lowest water loading, 30\%92S6, and that it shows a weaker temperature dependence. This suggests that near the pore surface, the presence of the water-hydroxylated silica pair correlation might enable the persistence of nonhydrogen-bonded water and also prevent ice formation.

\section{Acknowledgements}

We thank Professor Rachida Dorbez-Sridi for providing 92S6 samples and Professor Mirijam Zobel for helpful discussions. We acknowledge SOLEIL and ESRF for provision of synchrotron radiation facilities and we would like to thank Dr Erik Elkaim for assistance in using beamline CRISTAL at SOLEIL (project No. 20170792) as well as Dr Agnieszka Poulain in using beamline ID31 at the ESRF (project No. MA3925). The authors thank the reviewers for their helpful remarks and constructive suggestions. This work was supported by the Université de Lorraine, the CNRS and the Institut Jean Barriol, which are gratefully acknowledged. H. Khoder is indebted to the French Ministry of Research for a doctoral fellowship.

\section{References}

Akporiaye, D., Hansen, E. W., Schmidt, R. \& Stocker, M. (1994). J. Phys. Chem. 98, 1926-1928.

Alba-Simionesco, C., Coasne, B., Dosseh, G., Dudziak, G., Gubbins, K. E., Radhakrishnan, R. \& Sliwinska-Bartkowiak, M. (2006). J. Phys. Condens. Matter, 18, R15-R68.

Allen, M. P. \& Tildesley, D. J. (1987). Computer Simulation of Liquids. UK: Oxford University Press, New York: Clarendon Press.

Bchellaoui, N., Hayat, Z., Mami, M., Dorbez-Sridi, R. \& El Abed, A. I. (2017). Sci. Rep. 7, 1-10.

Bellissent-Funel, M., Lal, J. \& Bosio, L. (1993). J. Chem. Phys. 98, 4246-4252. 
Bellissent-Funel, M., Sridi-Dorbez, R. \& Bosio, L. (1996). J. Chem. Phys. 104, 10023-10029.

Bogdan, A., Kulmala, M. \& Avramenko, N. (1998). Phys. Rev. Lett. 81, 1042-1045.

Bowron, D. T. (2008). Mater. Sci. Eng. B, 149, 166-170.

Bowron, D. T. (2014). Procedia Mater. Sci. 7, 38-52.

Bruni, F., Ricci, M. A. \& Soper, A. K. (1998). J. Chem. Phys. 109, 1478-1485.

Faraone, A., Liu, L., Mou, C.-Y., Yen, C.-W. \& Chen, S.-H. (2004). J. Chem. Phys. 121, 10843-10846.

Findenegg, G. H., Jähnert, S., Akcakayiran, D. \& Schreiber, A. (2008). ChemPhysChem, 9, 2651-2659.

Fouzri, A., Dorbez-Sridi, R., Nasr, S. \& Oumezzine, M. (2002). Biomol. Eng. 19, 207-210.

Fouzri, A., Dorbez-Sridi, R., Oumezzine, M. \& Missaoui, A. (2001). Int. J. Inorg. Mater. 3, 1315-1317.

Grünberg, B., Emmler, T., Gedat, E., Shenderovich, I., Findenegg, G. H., Limbach, H.-H. \& Buntkowsky, G. (2004). Chem. Eur. J. 10, 5689-5696.

Hansen, E. W., Gran, H. C. \& Sellevold, E. J. (1997). J. Phys. Chem. B, 101, 7027-7032.

Hansen, E. W., Schmidt, R., Stoecker, M. \& Akporiaye, D. (1995). J. Phys. Chem. 99, 4148-4154.

Hench, L. \& Wilson, J. (1984). Science, 226, 630-636.

Hench, L. L. \& Polak, J. M. (2002). Science, 295, 1014-1017.

Hench, L. L., Splinter, R. J., Allen, W. C. \& Greenlee, T. K. (1971). J. Biomed. Mater. Res. 5, 117-141.

Hsieh, K.-Y., Bendeif, E.-E., Gansmuller, A., Pillet, S., Woike, T. \& Schaniel, D. (2013). RSC Adv. 3, 26132.

Ishikiriyama, K. \& Todoki, M. (1995). Thermochim. Acta, 256, $213-$ 226.

Izquierdo-Barba, I., Arcos, D., Sakamoto, Y., Terasaki, O., LópezNoriega, A. \& Vallet-Regí, M. (2008). Chem. Mater. 20, 31913198.

Jones, J. R. (2013). Acta Biomater. 9, 4457-4486.

Jones, J. R., Ehrenfried, L. M. \& Hench, L. L. (2006). Biomaterials, 27, 964-973.

Kamitakahara, W. A., Faraone, A., Liu, K.-H. \& Mou, C.-Y. (2012). J. Phys. Condens. Matter, 24, 064106.

Karakassides, M. A., Saranti, A. \& Koutselas, I. (2004). J. Non-Cryst. Solids, 347, 69-79.

Kaur, G., Pickrell, G., Sriranganathan, N., Kumar, V. \& Homa, D. (2016). J. Biomed. Mater. Res. 104, 1248-1275.

Kittaka, S., Ishimaru, S., Kuranishi, M., Matsuda, T. \& Yamaguchi, T. (2006). Phys. Chem. Chem. Phys. 8, 3223.

Kittaka, S., Sou, K., Yamaguchi, T. \& Tozaki, K. (2009). Phys. Chem. Chem. Phys. 11, 8538.

Kresge, C. T., Leonowicz, M. E., Roth, W. J., Vartuli, J. C. \& Beck, J. S. (1992). Nature, 359, 710-712.

Lee, S. H. \& Rossky, P. J. (1994). J. Chem. Phys. 100, 3334-3345.

Li, R., Clark, A. E. \& Hench, L. L. (1991). J. Appl. Biomater. 2, 231239.

Lusvardi, G., Malavasi, G., Cortada, M., Menabue, L., Menziani, M. C., Pedone, A. \& Segre, U. (2008). J. Phys. Chem. B, 112, 1273012739.

Mancinelli, R., Imberti, S., Soper, A. K., Liu, K. H., Mou, C. Y., Bruni, F. \& Ricci, M. A. (2009). J. Phys. Chem. B, 113, 16169-16177.

Morishige, K. \& Iwasaki, H. (2003). Langmuir, 19, 2808-2811.
Morishige, K. \& Kawano, K. (1999). J. Chem. Phys. 110, 4867-4872. Morishige, K. \& Uematsu, H. (2005). J. Chem. Phys. 122, 044711.

Morishige, K., Yasunaga, H., Denoyel, R. \& Wernert, V. (2007). J. Phys. Chem. C, 111, 9488-9495.

Proffen, Th., Billinge, S. J. L., Egami, T. \& Louca, D. (2003). Z. Kristallogr. Cryst. Mater. 218, 132-143.

Qiu, X., Thompson, J. W. \& Billinge, S. J. L. (2004). J. Appl. Cryst. 37, 678.

Ravikovitch, P. I., Domhnaill, S. C. O., Neimark, A. V., Schueth, F. \& Unger, K. K. (1995). Langmuir, 11, 4765-4772.

Ravikovitch, P. I. \& Neimark, A. V. (2001). J. Phys. Chem. B, 105, 6817-6823.

Rennie, G. K. \& Clifford, J. (1977). J. Chem. Soc. Faraday Trans. 1, 73, 680.

Rovere, M., Ricci, M. A., Vellati, D. \& Bruni, F. (1998). J. Chem. Phys. 108, 9859-9867.

Salinas, A. J., Martin, A. I. \& Vallet-Regí, M. (2002). J. Biomed. Mater. Res. 61, 524-532.

Salinas, A. J. \& Vallet-Regí, M. (2013). RSC Adv. 3, 11116.

Schmidt, R., Hansen, E. W., Stoecker, M., Akporiaye, D. \& Ellestad, O. H. (1995). J. Am. Chem. Soc. 117, 4049-4056.

Schreiber, A., Ketelsen, I. \& Findenegg, G. H. (2001). Phys. Chem. Chem. Phys. 3, 1185-1195.

Smirnov, P., Yamaguchi, T., Kittaka, S., Takahara, S. \& Kuroda, Y. (2000). J. Phys. Chem. B, 104, 5498-5504.

Soper, A. K. (1996). Chem. Phys. 202, 295-306.

Soper, A. K. (2001). Mol. Phys. 99, 1503-1516.

Soper, A. K. (2008). Mol. Phys. 106, 2053-2076.

Soper, A. K. (2012). J. Phys. Condens. Matter, 24, 064107.

Soper, A. K. (2013). Chem. Phys. Lett. 590,1-15.

Soper, A. K., Bruni, F. \& Ricci, M. A. (1998). J. Chem. Phys. 109, 1486-1494.

Stefanutti, E., Bove, L. E., Lelong, G., Ricci, M. A., Soper, A. K. \& Bruni, F. (2019). Phys. Chem. Chem. Phys. 21, 4931-4938.

Steytler, D. C., Dore, J. C. \& Wright, C. J. (1983). J. Phys. Chem. 87, 2458-2459.

Takahara, S., Nakano, M., Kittaka, S., Kuroda, Y., Mori, T., Hamano, H. \& Yamaguchi, T. (1999). J. Phys. Chem. B, 103, 5814-5819.

Takamuku, T., Yamagami, M., Wakita, H., Masuda, Y. \& Yamaguchi, T. (1997). J. Phys. Chem. B, 101, 5730-5739.

Thompson, H., Soper, A. K., Ricci, M. A., Bruni, F. \& Skipper, N. T. (2007). J. Phys. Chem. B, 111, 5610-5620.

Tilocca, A. (2009). Proc. R. Soc. A, 465, 1003-1027.

Tilocca, A., Cormack, A. N. \& de Leeuw, N. H. (2007). Chem. Mater. 19, 95-103.

Tombari, E., Salvetti, G., Ferrari, C. \& Johari, G. P. (2005). J. Chem. Phys. 122, 104712.

Turdean-Ionescu, C., Stevensson, B., Izquierdo-Barba, I., García, A., Arcos, D., Vallet-Regí, M. \& Edén, M. (2016). J. Phys. Chem. C, 120, 4961-4974.

Webber, J. B. W., Dore, J. C., Strange, J. H., Anderson, R. \& Tohidi, B. (2007). J. Phys. Condens. Matter, 19, 415117.

Yamanaka, K., Yamaguchi, T. \& Wakita, H. (1994). J. Chem. Phys. 101, 9830-9836.

Yoshida, K., Yamaguchi, T., Kittaka, S., Bellissent-Funel, M.-C. \& Fouquet, P. (2008). J. Chem. Phys. 129, 054702.

Zhao, D., Feng, J., Huo, Q., Melosh, N., Fredrickson, G. H., Chmelka, B. F. \& Stucky, G. D. (1998). Science, 279, 548-552. 